\title{
MODERATING EFFECTS OF RELIGIOSITY IN THE GENETIC AND ENVIRONMENTAL ETIOLOGY OF THE BIG FIVE PERSONALITY TRAITS IN ADULTHOOD
}

\author{
Shinji YAMAGATA ${ }^{1)}$ and Yusuke TAKAHASHI ${ }^{2)}$ \\ ${ }^{1)}$ Nagoya University, Japan \\ ${ }^{2)}$ Kyoto University, Japan
}

\begin{abstract}
This study examined whether religiosity moderates the genetic and environmental etiology of the Big Five personality traits (Neuroticism, Extraversion, Openness to Experience, Agreeableness, and Conscientiousness). Data from a nationwide sample of 549 twin pairs collected through the MacArthur Foundation National Survey of Midlife Development in the United States were analyzed. Analyses of a gene-environment interaction model revealed that religiosity moderated the magnitude of genetic and environmental influences on Agreeableness and Conscientiousness; for those who were religious, environmental influences on Agreeableness and genetic influences on Conscientiousness were greater. Religiosity exhibited weak main effects on both traits, with higher religiosity contributing to higher levels of both traits. These results suggested that religiosity serves as a psychological immune system that restricts individuals' levels of Agreeableness and Conscientiousness within a religiously appropriate range, insulating them from internal and external forces. Implications for personality theory and molecular genetic research on personality and psychopathology are discussed.
\end{abstract}

Key words: religiosity, personality, Gene $\times$ Environment interaction, twin study, Midlife Development in the United States (MIDUS)

One conclusion that can reasonably be drawn from past behavioral genetic research is that almost every stable individual difference is heritable (Plomin et al., 2016; Polderman et al., 2015; Turkheimer, 1998). Beyond physical traits such as height and weight, genetic influences have also been observed in various psychological and behavioral traits such as personality traits, intelligence, self-esteem, social attitudes, and even the experience of life events (Plomin et al., 2016). However, another conclusion from behavioral genetic research is that environments are as important as genes. For example, one of the most heritable psychological traits in adulthood is intelligence, but genetic influences can explain only two-thirds of the observed variation (Haworth et al., 2010). Thus, the simple "nature or nurture" debate should have ended with the realization that both genetics and environment are important.

However, the relationship between genetics and environment is much more complex than the original framing. Behavioral genetic research shows that genes are expressed

Correspondence concerning this article should be addressed to Shinji Yamagata, Ph.D., Graduate School of Education and Human Development, Nagoya University, Japan (e-mail: yamagata.shinji@k.mbox.nagoyau.ac.jp). 
differentially across different environments, a phenomenon called Gene $\times$ Environment $(\mathrm{G} \times \mathrm{E})$ interaction. For example, genetics exert a stronger influence on alcohol use among adolescents in urban areas than in rural areas, where family environment plays a greater role (Rose et al., 2001), and genetic influences on depressive symptoms are greater for unmarried than for married women (Heath et al., 1998). Moreover, two principal domains of facial perception, namely facial recognition and judgement of facial attractiveness, have distinct etiologies; the former can be explained primarily by genetic influences, and the latter by environmental influences (Germine et al., 2015). Although environmental variables in the above examples are dichotomous (i.e., rural vs. urban, married vs. unmarried, and perception vs. social judgement), a statistical technique makes it possible to analyze the interaction between genetics and continuous environmental variables (Purcell, 2002). Using this technique, Dick et al. (2001) have shown that genetic influences on the frequency of alcohol use among adolescents are greater for those residing in communities with more migration into and out of the community, in other words, a more anonymous environment. In another example, Turkheimer et al. (2003) demonstrated that genetic influences on IQ among young children were negligible for those from impoverished families, but that genetic influence increased as families became more affluent. Finally, Johnson and Krueger (2005) demonstrated that genetic influences on physical health among adults were larger for those with higher income or with a greater sense of control over their lives.

However, surprisingly few studies have examined $G \times E$ interaction in the context of the etiology of personality traits, one of the most-studied phenotypes in human behavioral genetics. Examining $\mathrm{G} \times \mathrm{E}$ interaction in the etiology of personality traits is significant for several reasons. First, it has implications for the debate on personality theory. Based on findings from behavioral genetic research on personality traits (summarized in Bouchard \& Loehlin, 2001), McCrae and Costa (1999) and McCrae (2004) proposed the Five Factor Theory (FFT), arguing that the five key personality traits (Neuroticism, Extraversion, Openness to Experience, Agreeableness, and Conscientiousness) are solely biologically determined. According to the FFT, these five traits are substantially genetically influenced, and the remaining variance can be explained by measurement errors or by biological events such as the intrauterine environment, aging, and disease, but not by systematic influences of the psychosocial environment (e.g., marriage, experience of stressful life events, etc.). Other theorists (e.g., Lodi-Smith \& Roberts, 2007; Roberts et al., 2005) have opposed this argument, showing that many aspects of the psychosocial environment influence the development of personality traits (i.e., social investment theory). However, a meta-analysis showed that when a genetically informative design (e.g., a twin study) was used, the influences of single measured environmental variables on personality were quite limited (Turkheimer \& Waldron, 2000). Although, whether specific psychosocial environments have main effects on personality traits remains a matter of debate, another way to test the FFT is to examine the moderating role of the psychosocial environment. Because the FFT does not predict that genetic and biological influences on personality are moderated by the psychosocial environment, finding such phenomena would provide evidence against the FFT. 
Second, because personality traits are regarded as being on a continuum with mental disorders or as vulnerability factors for mental disorders (e.g., Markon et al., 2005), finding environments that suppress expression of the genes influencing personality would provide clues to effective environmental interventions for individuals who are particularly at risk for mental disorders. Similarly, if environments that maximize expression of genes that influence personality were found, this could be of use in linkage and association studies searching for the molecular genetic basis of personality traits and mental disorders.

To date, only a few studies have examined $\mathrm{G} \times \mathrm{E}$ interaction for personality traits. One such study was conducted by Boomsma et al. (1999). They examined whether the genetic and environmental etiology of disinhibition (e.g., desires for social drinking, partying, and a variety of sexual partners) were moderated by religious upbringing. Using data from adolescent twins, they observed that genetic influences on disinhibition were smaller, and family (shared) environmental influences were larger, for those who were brought up in religious families than for those who were not. Because religious activities provide family members with more opportunity to interact and share experiences and because religious fathers and mothers tend to be more involved in childrearing (Pearce \& Axinn, 1998), such reduced genetic and increased shared environmental influences in religious families make sense. Related to that study, Hur et al. (2019) demonstrated that frequent religious attendance showed the influence of environment-environment interaction on prosocial behavior, which could be likened to Agreeableness, indicating that nonshared environmental influences decreased among Nigerian adolescents with more frequent religious attendance. However, these previous studies have several limitations. First, the researchers measured only one personality trait (i.e., disinhibition, prosociality); thus, the moderating role of religious upbringing on FFT personality traits is still unclear. Second, Boomsma et al. (1999), in particular, measured religious upbringing as a dichotomous rather than a continuous variable (i.e., the extent to which a family raises their children in religious ways). In analyzing $\mathrm{G} \times \mathrm{E}$ interaction, a continuous environmental moderator is preferred to a dichotomous moderator in that the former can more precisely describe how genetic and environmental influences change with varying levels of moderating environmental variables (e.g., linear vs. nonlinear change) and can also retain more statistical power. Third, because the samples used in both Boomsma et al.'s (1999) and Hur et al.'s (2019) studies comprised young adolescent twins, it was unclear whether the moderating influence of religious upbringing persisted into adulthood, where there is strong evidence that childhood family environment does not play a role in explaining personality traits (Bouchard et al., 1998).

The present study aimed, therefore, to examine whether genetic influences on all of the FFT personality traits in an adult twin sample were moderated by individuals' religiosity, treating religiosity as a continuous moderator variable with an adult twin sample. Although religiosity is different from religious upbringing per se, the literature shows that religiosity is substantially influenced by family environmental influences and is among the least heritable of traits (Winter et al., 1999; Koenig, McGue, \& Iacono, 2005; but see also Koenig, McGue, Krueger, \& Bouchard, 2005). Thus, religiosity can 
be considered a more proximal variable than religious upbringing for moderating the etiology of personality traits.

\section{METHOD}

\section{Participants}

This study used the twin sample from the MacArthur Foundation National Survey of Midlife Development in the United States (MIDUS; Brim et al., 2004). In that survey, twin pairs were recruited by a two-part sampling design. In the first part of the design, two research organizations, ICR/AUS Consultants and Bruskin Associates, made telephone calls to a representative national sample of approximately 50,000 households and asked respondents whether they or any of their immediate family members were members of twin pairs. Among respondents, $14.8 \%$ reported the presence of twin siblings in the family; of these, $60.0 \%$ gave permission to be contacted for the twin study. In the second part of the design, student recruiters from the University of Michigan contacted the twins to participate in MIDUS. The cooperating twins were asked to provide contact information for their co-twins, who were then also recruited by the students. The final response rate for the twin pairs varied according to whether the initial contact was with a relative of the twin (20.6\% response rate) or with the twin him- or herself $(60.4 \%$ response rate). The final twin sample included a total of 1,996 twins, resulting in 998 pairs (see Kessler et al., 2004, for additional details).

Eight standard zygosity self-report items were used to determine whether the twins were identical (monozygotic [MZ]) or fraternal (dizygotic [DZ]). The classification rule was developed by reference to data from the Virginia Twin Registry, which used the same items as MIDUS. In total, 230 same-sex twin pairs were genotyped for zygosity determination. Ultimately, $86.0 \%$ of the pairs were assigned a probability of either $<10 \%$ or $>90 \%$ of being MZ, and an additional $10.5 \%$ of the pairs were assigned a probability of $<40 \%$ or more than $>60 \%$ of being MZ. The remaining $3.5 \%$ of the pairs were excluded from the study (see Kendler et al., 2000; Kessler et al., 2004, for additional details). For the present study, we used 549 same-sex pairs for whom we had complete data specific to the Big Five personality traits and religiosity, resulting in 133 male MZ pairs, $163 \mathrm{MZ}$ female pairs, $93 \mathrm{DZ}$ male pairs, and $148 \mathrm{DZ}$ female pairs. The mean age of the sample was $44.90(S D=11.98)$ years (for more demographic information about the twin sample, see Johnson \& Krueger, 2005).

\section{Measurement}

The Big Five personality traits were assessed using 25 self-descriptive adjectives selected from previous Big Five inventories (cf. John, 1990). For example, items pertaining to Agreeableness were helpful, warm, caring, softhearted, sympathetic. Respondents rated the degree to which each item described them using a four-point Likert scale ("A lot" to "Not at all"). Because age and gender effects bias behavioral genetic analyses, each personality score was adjusted for these effects by regressing each on age and gender and then using the residual score in all subsequent analyses. Religiosity was assessed by summing the scores for six questions, including "How religious are you?" and "How closely do you identify with being a member of your religious group?" These questions were answered using a four-point Likert scale ("Very" to "Not at all"; for more details on the Big Five and religiosity scales, see Midlife in the United States, 2004).

\section{Statistical Analysis}

Traditional univariate genetic analysis was used to decompose the observed (phenotypic) variance $(P)$ into variances in additive genetic $\left(a^{2}\right)$, family (common) environmental $\left(c^{2}\right)$, and nonshared environmental $\left(e^{2}\right)$ influences (Knopik et al., 2016). In equation form, this is represented as

$$
v(P)=a^{2}+c^{2}+e^{2}
$$

The additive genetic influences variable (A, represented in equation 1 as a) reflects variation in multiple genotypes whose influences are small and additive and, which, together, form a quantitative 
phenotype. The family environmental influences variable $(\mathrm{C} ; c$ in equation 1$)$ reflects variation in environmental characteristics that make family members alike and that differ between families. The nonshared environmental influences variable (E; $e$ in equation 1) reflects variation in environmental characteristics that make family members different from one another even if they live together, such as physical illness and differential parental treatment, and also includes measurement errors.

The $\mathrm{G} \times \mathrm{E}$ interaction model (Purcell, 2002) allows the magnitude of influences of $\mathrm{A}, \mathrm{C}$, and $\mathrm{E}$ on personality to vary as a function of religiosity $(R E L)$. In equation form, this is represented as

$$
v(P)=\left(a+\beta_{a} R E L+\beta^{\prime} R E L^{2}\right)^{2}+\left(c+\beta_{c} R E L+\beta^{\prime} R E L^{2}\right)^{2}+\left(e+\beta_{e} R E L+\beta^{\prime}{ }_{e} R E L^{2}\right)^{2},
$$

where $R E L$ and $R E L^{2}$ reflect the participants' standardized and squared scores for religiosity, respectively. In this equation, $a, c$, and $e$ are the main effects of $\mathrm{A}, \mathrm{C}$, and $\mathrm{E}$; and $\beta_{a}, \beta_{c}, \beta_{e}$, and $\beta^{\prime}{ }_{a}, \beta^{\prime}{ }_{c}$, and $\beta^{\prime}{ }_{e}$ are linear and nonlinear interactions, respectively, of $\mathrm{A}, \mathrm{C}$, and $\mathrm{E}$ with religiosity. For example, the statistical significance of $\beta_{a}$ indicates the presence of linear $G$ (genetic influences on personality) $\times$ religiosity interaction. The model also allows us to examine linear and nonlinear $\mathrm{C}$ (family environmental influences) $\times$ religiosity and $\mathrm{E}$ (nonshared environmental influences) $\times$ religiosity interactions. Because religiosity may also have main effects on personality, the mean structure of each personality trait was also modeled as $\mu+$ $\beta_{m} R E L$, where $\mu$ is the overall mean of personality, and $\beta_{m}$ is the main effect of religiosity. Models fixing or freeing each parameter were systematically compared using chi-square tests and Akaike's Information Criterion (AIC). All analyses were conducted using the computer program "classical" Mx (Neale et al., 2003).

\section{RESULTS}

To examine whether religiosity moderates genetic and environmental influences on personality traits, we first compared a full model including all moderating effects to the ACE model with no moderating effects. All moderating effects could be dropped without significant decrement in fit for Neuroticism $\left(\Delta \chi^{2}(6)=2.89, p=.82\right.$, AIC $=-77.66$ as compared with the full model, AIC $=-68.55)$, Extraversion $\left(\Delta \chi^{2}(6)=5.31, p=.51\right.$, AIC $=-407.01$ as compared with the full model, AIC $=-400.32)$, and Openness to Experience $\left(\Delta \chi^{2}(6)=1.97, p=.92\right.$, AIC $=-584.37$ as compared with the full model, $\mathrm{AIC}=-574.34)$. However, dropping all moderating parameters resulted in significant decrement in fit for Agreeableness $\left(\Delta \chi^{2}(6)=15.52, p<.05\right.$, AIC $=-911.30$ as compared with the full model, AIC $=-914.82)$ and Conscientiousness $\left(\Delta \chi^{2}(6)=15.79, p<.05\right.$, AIC $=-999.63$ as compared with the full model, AIC $=-1003.42)$. Thus, for the two latter personality traits, we decided to test the significance of each parameter individually.

As Table 1 summarizes, for Agreeableness, the main effects of $\mathrm{C}$ and all moderating parameters except linear moderation effects of $\mathrm{E}$ could be dropped without significant decrement in fit as compared with the full model. The main effect of religiosity in the mean structure could not be dropped. The selected model (AE model with linear moderation of $\mathrm{E}$ as well as a main effect of religiosity) fit better than the full model $\left(\Delta \chi^{2}\right.$ $(6)=6.14, p=.41, \mathrm{AIC}=-920.68$ as compared with the full model, AIC $=-914.82)$ or $\mathrm{ACE}(\mathrm{AIC}=-911.30)$ and the AE model $(\mathrm{AIC}=-913.30)$. For Conscientiousness, the main effect of $\mathrm{C}$ and all moderating parameters except linear moderation effects of $\mathrm{A}$ could be dropped without significant decrement in fit as compared with the full model. The main effect of religiosity in the mean structure could not be dropped. The selected 
Table 1. Results of $\mathrm{G} \times \mathrm{E}$ Interaction Analyses for Agreeableness and Conscientiouness

\begin{tabular}{|c|c|c|c|c|c|}
\hline Question & Answer & $-2 L L$ & $d f$ & $p$ & $\mathrm{AIC}$ \\
\hline \multicolumn{6}{|l|}{ Agreeableness } \\
\hline How does full model fit? & & 1211.18 & 1063 & & -914.82 \\
\hline Can all the moderation effects be fixed at 0 ? (ACE model) & No & 15.52 & 6 & .02 & -911.30 \\
\hline Can the linear moderation effects on $\mathrm{A}$ be fixed at 0 ? & Yes & 3.04 & 1 & .08 & -913.78 \\
\hline Can the linear moderation effects on $\mathrm{C}$ be fixed at 0 ? & Yes & 1.30 & 1 & .26 & -915.52 \\
\hline Can the linear moderation effects on $\mathrm{E}$ be fixed at 0 ? & No & 4.23 & 1 & .04 & -912.59 \\
\hline Can the nonlinear moderation effects on $\mathrm{A}$ be fixed at 0 ? & Yes & 2.89 & 1 & .09 & -913.93 \\
\hline Can the nonlinear moderation effects on $\mathrm{C}$ be fixed at 0 ? & Yes & 0.40 & 1 & .53 & -916.42 \\
\hline Can the nonlinear moderation effects on $\mathrm{E}$ be fixed at 0 ? & Yes & 0.01 & 1 & .92 & -916.81 \\
\hline Can the main $\mathrm{C}$ effects be fixed at 0 ? & Yes & 1.67 & 1 & .20 & -915.15 \\
\hline Can the main effects of religiosity be fixed at 0 ? & No & 26.92 & 1 & .00 & -889.90 \\
\hline How does the selected model fit? & & 6.14 & 6 & .41 & -920.68 \\
\hline Is the selected model better than AE model? & Yes & 15.52 & 7 & .03 & -913.30 \\
\hline Conscientiousness & Answer & & & & \\
\hline How does full model fit? & & 1122.58 & 1063 & & -1003.42 \\
\hline Can all the moderation effects be fixed at 0 ? (ACE model) & No & 15.79 & 6 & .02 & -999.63 \\
\hline Can the linear moderation effects on $\mathrm{A}$ be fixed at 0 ? & No & 5.76 & 1 & .02 & -999.66 \\
\hline Can the linear moderation effects on $\mathrm{C}$ be fixed at 0 ? & Yes & 2.20 & 1 & .14 & -1003.22 \\
\hline Can the linear moderation effects on $\mathrm{E}$ be fixed at 0 ? & Yes & 0.12 & 1 & .73 & -1005.30 \\
\hline Can the nonlinear moderation effects on $\mathrm{A}$ be fixed at 0 ? & Yes & 0.46 & 1 & .50 & -1004.96 \\
\hline Can the nonlinear moderation effects on $\mathrm{C}$ be fixed at 0 ? & Yes & 0.01 & 1 & .94 & -1005.41 \\
\hline Can the nonlinear moderation effects on $\mathrm{E}$ be fixed at 0 ? & Yes & 0.05 & 1 & .83 & -1005.37 \\
\hline Can the main $\mathrm{C}$ effects be fixed at 0 ? & Yes & 0.06 & 1 & .81 & -1005.36 \\
\hline Can the main effects of religiosity be fixed at 0 ? & No & 6.48 & 1 & .01 & -998.93 \\
\hline How does the selected model fit? & & 2.90 & 6 & .82 & -1012.52 \\
\hline Is the selected model better than AE model? & Yes & 15.79 & 7 & .03 & -1001.63 \\
\hline
\end{tabular}

model (AE model with linear moderation of $\mathrm{E}$ and a main effect of religiosity) fit better than the full model $\left(\Delta \chi^{2}(6)=2.90, p=.82\right.$, AIC $=-1012.52$ as compared with the full model, $\mathrm{AIC}=-1003.42)$ or ACE $(\mathrm{AIC}=-999.63)$ and $\mathrm{AE}$ model $(\mathrm{AIC}=-1001.63)$.

Table 2 summarizes the estimated parameters. For Agreeableness, the sign of the estimated moderation of $\mathrm{E}$ was negative $(-.031,95 \%$ confidence interval [CI; -.052 , $-.011]$ ), indicating that the effects of nonshared environmental influences were smaller 
Table 2. Estimated Parameters for the Selected Models

\begin{tabular}{lcc}
\hline \multicolumn{1}{c}{ Parameter } & Agreeableness & Conscientiousness \\
\hline Genetic variance & $.047(.028, .067)$ & $.079(.061, .099)$ \\
Nonshared environmental variance & $.140(.121, .161)$ & $.100(.086, .116)$ \\
Linear moderation to A & - & $-.051(-.081,-.023)$ \\
Linear moderation to E & $-.031(-.052,-.011)$ & - \\
Main effects of religiosity & $.074(.047, .102)$ & $.037(.010, .065)$ \\
Heritability (Religiosity $=-2 S D)$ & $.20(.12, .29)$ & $.59(.49, .68)$ \\
Heritability (Religiosity $=0)$ & $.25(.15, .35)$ & $.44(.35, .52)$ \\
Heritability (Religiosity $=2 S D)$ & $.32(.19, .46)$ & $.24(.10, .39)$ \\
\hline
\end{tabular}

Note. The $95 \%$ confidence intervals are shown within parentheses.
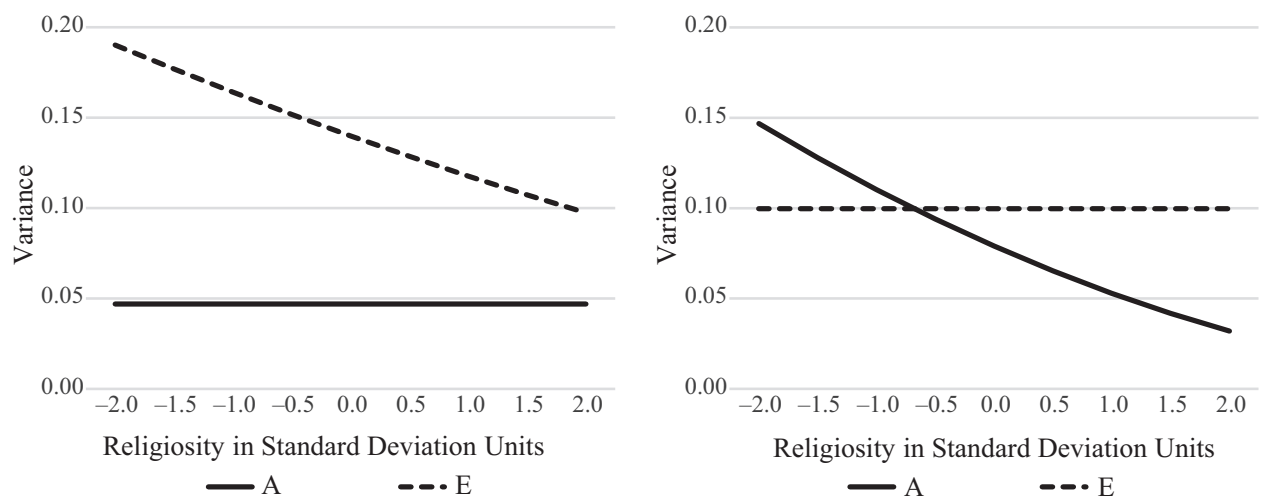

Fig. 1. Variance of Agreeableness (left) and Conscientiousness (right) as a Function of Religiosity Note. $\mathrm{A}=$ genetic variance, $\mathrm{E}=$ nonshared environmental variance. Because linear interaction is in terms of effect, a plot of variance looks like quadratic curve.

for those with higher levels of religiosity. For Conscientiousness, the sign of the estimated moderation of A was also negative (-.051, 95\% CI [-.081, -.023]), indicating that genetic influences were smaller for those with higher levels of religiosity. For both personality traits, the sign of the main effect of religiosity was positive $(.047,95 \% \mathrm{CI}$ [.028, .067] for Agreeableness; .079, 95\% CI [.061, .099] for Conscientiousness), indicating that high religiosity not only decreased variance but also heightened levels of the two personality traits. When we computed heritability estimates for Agreeableness and Conscientiousness among those with different levels of religiosity, we found that the heritability of Agreeableness increased with one's level of religiosity $\left(h^{2}=.20\right.$ for individuals with $-2 S D$ religiosity vs. $h^{2}=.32$ for those with $+2 S D$ religiosity), whereas the heritability of Conscientiousness decreased as the level of religiosity increased $\left(h^{2}=\right.$ .59 for individuals with $-2 S D$ religiosity vs. $h^{2}=.24$ for those with $+2 S D$ religiosity). 
These results are graphically summarized in Fig. 1. As the figure indicates, the differences between Agreeableness and Conscientiousness in heritability reflected different genetic and environmental etiologies. While the differential heritability of Agreeableness was due to changes in environmental influences (Environment $\times$ Environment $[\mathrm{E} \times \mathrm{E}]$ interaction), that of Conscientiousness was due to changes in genetic influences $(\mathrm{G} \times \mathrm{E}$ interaction).

\section{Discussion}

This study found that religiosity moderated the genetic and environmental etiologies of Agreeableness and Conscientiousness, but not of the other three personality traits (Neuroticism, Extraversion, and Openness to Experience). Also, higher religiosity was associated with higher Agreeableness and Conscientiousness. These findings were consistent with a meta-analysis (Saroglou, 2002) showing that, among the FFT personality traits, Agreeableness and Conscientiousness were most strongly related with religiosity ( $r=.20$ for Agreeableness, $r=.17$ for Conscientiousness). Such a pattern is understandable given that being nice to other people and being responsible are both important principles in most religions. This study added to our prior knowledge the notion that religiosity not only heightens the levels of Agreeableness and Conscientiousness but also restricts the range of these two personality traits; specifically, religiosity helps people to maintain certain levels of Agreeableness and Conscientiousness by reducing the impact of environmental influences on Agreeableness and that of genetic influences on Conscientiousness. Also consistent with the present finding is the work of Jorm and Christensen (2004, Table 2), who showed that phenotypic variance in Psychoticism (the inverse of both Agreeableness and Conscientiousness; Eysenck, 1992) was consistently smallest in the quartile with the highest religiosity, irrespective of age and gender. Probably, then, religion can serve as a psychosocial immune system against internal and external forces, restricting the range of the two personality traits as appropriate to one's religion.

The present findings are both consistent and at odds with a previous twin study that examined the moderating role of religious attendance (Hur et al., 2019) and religious upbringing (Boomsma et al., 1999). Consistent with the present finding on Agreeableness, Hur et al. (2019) found that environmental influences on prosocial behavior, which is moderately positively correlated with Agreeableness (e.g., Hilbig et al., 2014; Graziano $\&$ Tobin, 2009), was smaller for those from religious families. When a hypothesis that religious belief facilitates prosocial behavior or Agreeableness (the religious prosociality hypothesis; Norenzayan \& Shariff, 2008) is considered, religious upbringing may reduce environmental influence on offspring's Agreeableness through fostering religiosity that maintains high level of Agreeableness unchanged across different environmental circumstances. Likewise, consistent with the present finding on Conscientiousness, Boomsma et al. (1999) found that genetic influences on disinhibition, a personality trait that is moderately negatively correlated with Conscientiousness (e.g., Naragon-Gainey \& 
Simms, 2017), were smaller for those from religious than those from non-religious families. However, they also observed that family environmental influences were larger for those from religious families, whereas in the present study, family environmental influences had negligible impact across all levels of religiosity. A possible interpretation is that, although children's disinhibition in religious families is more strongly influenced by family environment, such influences are temporary and do not persist into adulthood, as is normally observed in the development of personality traits (Bouchard \& Loehlin, 2001). Alternatively, the religious upbringings of parents may moderate the magnitude of family environmental influences on disinhibition independently of later religiosity; for example, religious parents' increased involvement with children (Pearce \& Axinn, 1998) may not be related to children's later religiosity, but may increase family environmental influences on children's disinhibition that persist into adulthood. One way to test these competing interpretations would be to determine the etiology of religiosity itself; if religiosity is not influenced by family environment, then religiosity cannot mediate the moderating role of religious upbringing. An additional analysis showed that religiosity in our sample was affected by family environmental influences, but not to a strong degree $\left(h^{2}=.23, c^{2}=.35, e^{2}=.43\right)$, as also shown in previous research (e.g., Bradshaw \& Ellison, 2008). Thus, whether the moderating role of religiosity observed in the present study was derived from religious upbringing (family environment) or from other factors (i.e., genes and unique environment) remains unclear. However, at minimum, it is clear that religiosity as a phenotype moderated genetic and environmental influences on personality traits. Therefore, the results of the present study should be labeled as Environment $\times$ Phenotype $(\mathrm{E} \times \mathrm{P})$ interaction (in the case of Agreeableness) and as Gene $\times$ Phenotype $(\mathrm{G} \times \mathrm{P})$ interaction (in the case of Conscientiousness), rather than as $\mathrm{E} \times \mathrm{E}$ or $\mathrm{G} \times \mathrm{E}$. Future studies should clarify whether religious upbringing itself moderates the etiology of personality independently of the religiosity of offspring.

One of the implications of the present findings is that the etiology of personality traits is not as purely biological as predicted by the FFT. From the perspective of the FFT, personality is a product of genes and biological events such as the intrauterine environment and disease. Thus, according to the FFT, neither variation in environmental effects on Agreeableness nor genetic influences on Conscientiousness would be moderated by a psychological characteristic such as religiosity. The present findings are at odds with this prediction from the FFT; in particular, moderation of environmental influences on Agreeableness and of genetic influences on Conscientiousness is consistent with the findings of Hur et al. (2019) and Boomsma et al. (1999), respectively. Therefore, although several predictions from the FFT have been supported from a behavioral genetic perspective (e.g., Yamagata et al., 2006), predictions regarding the sources of environmental influences on personality may require revision.

The present findings also have implications for the study of psychopathology. Both Agreeableness and Conscientiousness are regarded as being on continua with internalizing disorders such as depression and anxiety and externalizing disorders such as antisocial personality disorder and substance use disorders (Kotov et al., 2010; NaragonGainey \& Simms, 2017). Thus, fostering a high level of religiosity may protect against 
the development of both internalizing and externalizing disorders for those who are especially at risk by reducing environmental influences on Agreeableness and genetic influences on Conscientiousness. Also, although it is difficult to pinpoint the genetic bases of complex phenotypes, given that the influence of each individual gene is relatively small, selecting non-religious individuals for linkage/association analysis of Conscientiousness would offer the advantage of increased statistical power because genetic influences are more salient among non-religious individuals than among religious ones. Similarly, the search for specific environments that influence Agreeableness may benefit from enrolling non-religious participants, as environmental influences are more salient among these populations than among religious individuals.

Finally, some methodological limitations should be noted. First, due to the limited sample size, the present study did not examine effects of specific religions. In the present sample, about $51 \%$ of respondents were Protestant, $27 \%$ were Catholic, $9 \%$ were none/atheist/agnostic, and 13\% were of other religions (Latter-Day Saints, Jehovah's Witness, Buddhist, etc.; for more details on the denominational affiliations of this sample, see King, 2003). It is plausible that the moderating effects of religiosity may vary depending on denominational affiliation. Similarly, we did not examine the effects of gender. Although gender differences in the genetic and environmental etiology of personality traits have not been generally reported (Hur et al., 2019), in Boomsma et al.'s (1999) studies, the moderating effects of religious upbringing were more pronounced for males. Thus, future studies should examine the effects of gender and denominational affiliation using larger samples. Also, the generalizability of the present findings to different cultures, such as European and Asian cultures, need to be examined in the future.

Despite these limitations, the present study is among the first to reveal that the genetic and environmental etiologies of the Big Five personality traits in adulthood are moderated by religiosity. The notion that "a personality trait is about $50 \%$ heritable" is correct (Polderman et al., 2015), but it is also wrong in that it deals with overall variation within a population and does not consider the specific conditions of each individual. Further attempts to examine the $\mathrm{G} \times \mathrm{E}$ interaction on personality traits will reveal more vividly why we are so different, each from the other: how genes and environment interact to create who we are.

\section{AUTHOR'S CONTRIBUTION}

S.Y. and Y.T. contributed to conception of the work. S.Y. conducted the analyses and first wrote the manuscript. Both of the authors revised the manuscript and confirmed its final version.

\section{CONFLICT OF INTEREST}

The authors declare no conflicts of interest. 


\section{REFERENCES}

Boomsma, D. I., de Geus, E. J. C., van Baal, G. C. M., \& Koopmans, J. R. (1999). A religious upbringing reduces the influence of genetic factors on disinhibition: Evidence for interaction between genotype and environment on personality. Twin Research, 2(2), 115-125. https://doi.org/10.1375/twin.2.2.115

Bouchard, T. J., Jr., \& Loehlin, J. C. (2001). Genes, evolution, and personality. Behavior Genetics, 31(3), 243-273. https://doi.org/10.1023/A:1012294324713

Bouchard, T. J., Jr., McGue, M., Hur, Y. M., \& Horn, J. M. (1998). A genetic and environmental analysis of the California Psychological Inventory using adult twins reared apart and together. European Journal of Personality, 12(5), 307-320. https://doi.org/10.1002/(SICI) 1099-0984(1998090) 12:5<307::AIDPER336>3.0.CO;2-K

Bradshaw, M., \& Ellison, C. G. (2008). Do genetic factors influence religious life? Findings from a behavior genetic analysis of twin siblings. Journal for the Scientific Study of Religion, 47(4), 529-544. https://doi.org/10.1111/j.1468-5906.2008.00425.x

Brim, O. G., Ryff, C. D., \& Kessler, R. C. (Eds.). (2004). How healthy are we?: A national study of wellbeing at midlife. University of Chicago Press.

Dick, D. M., Rose, R. J., Viken, R. J., Kaprio, J., \& Koskenvuo, M. (2001). Exploring gene-environment interactions: Socioregional moderation of alcohol use. Journal of Abnormal Psychology, 110(4), 625-632. https://doi.org/10.1037/0021-843X.110.4.625

Eysenck, H. J. (1992). A reply to Costa and McCrae. P or A and C-the role of theory. Personality and Individual Differences, 13(8), 867-868. https://doi.org/10.1016/0191-8869(92)90003-8

Germine, L., Russell, R., Bronstad, P. M., Blokland, G. A. M., Smoller, J. W., Kwok, H., Anthony, S. E., Nakayama, K., Rhodes, G., \& Wilmer, J. B. (2015). Individual aesthetic preferences for faces are shaped mostly by environments, not genes. Current Biology, 25(20), 2684-2689. https://doi.org/ 10.1016/j.cub.2015.08.048

Graziano, W. G., \& Tobin, R. M. (2009). Agreeableness. In M. R. Leary \& R. H. Hoyle (Eds.), Handbook of individual differences in social behavior (pp. 46-61). Guilford Press.

Haworth, C. M. A., Wright, M. J., Luciano, M., Martin, N. G., de Geus, E. J. C., van Beijsterveldt, C. E. M., Bartels, M., Posthuma, D., Boomsma, D. I., Davis, O. S. P., Kovas, Y., Corley, R. P., DeFries, J. C., Hewitt, J. K., Olson, R. K., Rhea, S.-A., Wadsworth, S. J., Iacono, W. G., McGue, M., . . Plomin, R. (2010). The heritability of general cognitive ability increases linearly from childhood to young adulthood. Molecular Psychiatry, 15(11), 1112-1120. https://doi.org/10.1038/mp.2009.55

Heath, A. C., Eaves, L. J., \& Martin, N. G. (1998). Interaction of marital status and genetic risk for symptoms of depression. Twin Research, 1(3), 119-122. https://doi.org/10.1375/twin.1.3.119

Hilbig, B. E., Glöckner, A., \& Zettler, I. (2014). Personality and prosocial behavior: Linking basic traits and social value orientations. Journal of Personality and Social Psychology, 107(3), 529-539. https: //doi.org/10.1037/a0036074

Hur, Y.-M., Jeong, H.-U., Ajose, F., \& Knafo-Noam, A. (2019). Religious attendance moderates the environmental effect on prosocial behavior in Nigerian adolescents. Twin Research and Human Genetics, 22(1), 42-47. https://doi.org/10.1017/thg.2018.71

John, O. P. (1990). The "Big Five" factor taxonomy: Dimensions of personality in the natural language and questionnaires. In L. A. Pervin (Ed.), Handbook of personality: Theory and research (pp. 66-100). Guilford Press.

Johnson, W., \& Krueger, R. F. (2005). Higher perceived life control decreases genetic variance in physical health: Evidence from a national twin study. Journal of Personality and Social Psychology, 88(1), 165-173. https://doi.org/10.1037/0022-3514.88.1.165

Jorm, A. F., \& Christensen, H. (2004). Religiosity and personality: Evidence for non-linear associations. Personality and Individual Differences, 36(6), 1433-1441. https://doi.org/10.1016/S0191-8869(03) 00239-3

Kendler, K. S., Thornton, L. M., Gilman, S. E., \& Kessler, R. C. (2000). Sexual orientation in a U.S. national sample of twin and nontwin sibling pairs. American Journal of Psychiatry, 157(11), 1843-1846. https://doi.org/10.1176/appi.ajp.157.11.1843

Kessler, R. C., Gilman, S. E., Thornton, L. M., \& Kendler, K. S. (2004). Health, well-being, and social 
responsibility in the MIDUS twin and sibling subsamples. In O. G. Brim, C. D. Ryff, \& R. C. Kessler (Eds.), How healthy are we?: A national study of well-being at midlife (pp. 124-152). University of Chicago Press.

King, V. (2003). The influence of religion on fathers' relationships with their children. Journal of Marriage and the Family, 65(2), 382-395. https://doi.org/10.1111/j.1741-3737.2003.00382.x

Knopik, V. S., Neiderhiser, J., DeFries, J. C., \& Plomin, R. (2016). Behavioral genetics (7th ed.). Worth.

Koenig, L. B., McGue, M., \& Iacono, W. G. (2005). The heritability of religiousness in adolescent adoptees. Behavior Genetics, 35(6), 809. https://doi.org/10.1007/s10519-005-7287-9

Koenig, L. B., McGue, M., Krueger, R. F., \& Bouchard, T. J. (2005). Genetic and environmental influences on religiousness: Findings for retrospective and current religiousness ratings. Journal of Personality, 73(2), 471-488. https://doi.org/10.1111/j.1467-6494.2005.00316.x

Kotov, R., Gamez, W., Schmidt, F., \& Watson, D. (2010). Linking "big” personality traits to anxiety, depressive, and substance use disorders: A meta-analysis. Psychological Bulletin, 136(5), 768-821. https://doi.org/10.1037/a0020327

Lodi-Smith, J., \& Roberts, B. W. (2007). Social investment and personality: A meta-analysis of the relationship of personality traits to investment in work, family, religion, and volunteerism. Personality and Social Psychology Review, 11(1), 68-86. https://doi.org/10.1177/1088868306294590

Markon, K. E., Krueger, R. F., \& Watson, D. (2005). Delineating the structure of normal and abnormal personality: An integrative hierarchical approach. Journal of Personality and Social Psychology, 88(1), 139-157. https://doi.org/10.1037/0022-3514.88.1.139

McCrae, R. R. (2004). Human nature and culture: A trait perspective. Journal of Research in Personality, 38(1), 3-14. https://doi.org/10.1016/j.jrp.2003.09.009

McCrae, R. R., \& Costa, P. T. (1999). A five-factor theory of personality. In L. A. Pervin \& O. P. John (Eds.), Handbook of personality: Theory and research (2nd ed., pp. 139-153). Guilford Press.

Midlife in the United States. (2004). Documentation of scales in MIDUS I. Retrieved March 26, 2019, from http://midus.wisc.edu/midus1/

Naragon-Gainey, K., \& Simms, L. J. (2017). Clarifying the links of conscientiousness with internalizing and externalizing psychopathology. Journal of Personality, 85(6), 880-892. https://doi.org/10.1111/ jopy. 12295

Neale, M., Boker, S. M., Xie, G., \& Maes, H. H. (2003). Mx: Statistical modelling (6th ed.). Mx. https: //www.vipbg.vcu.edu/media/downloads/pub/mx/mxmang23.pdf

Norenzayan, A., \& Shariff, A. F. (2008). The origin and evolution of religious prosociality. Science, 322(5898), 58-62. https://doi.org/10.1126/science.1158757

Pearce, L. D., \& Axinn, W. G. (1998). The impact of family religious life on the quality of mother-child relations. American Sociological Review, 63(6), 810-828. https://doi.org/10.2307/2657503

Plomin, R., DeFries, J. C., Knopik, V. S., \& Neiderhiser, J. M. (2016). Top 10 replicated findings from behavioral genetics. Perspectives on Psychological Science, 11(1), 3-23. https://doi.org/10.1177/ 1745691615617439

Polderman, T. J. C., Benyamin, B., de Leeuw, C. A., Sullivan, P. F., van Bochoven, A., Visscher, P. M., \& Posthuma, D. (2015). Meta-analysis of the heritability of human traits based on fifty years of twin studies. Nature Genetics, 47(7), 702-709. https://doi.org/10.1038/ng.3285

Purcell, S. (2002). Variance components models for gene-environment interaction in twin analysis. Twin Research, 5(6), 554-571. https://doi.org/10.1375/twin.5.6.554

Roberts, B. W., Wood, D., \& Smith, J. L. (2005). Evaluating Five Factor Theory and social investment perspectives on personality trait development. Journal of Research in Personality, 39(1), 166-184. https://doi.org/10.1016/j.jrp.2004.08.002

Rose, R. J., Dick, D. M., Viken, R. J., \& Kaprio, J. (2001). Gene-environment interaction in patterns of adolescent drinking: Regional residency moderates longitudinal influences on alcohol use. Alcoholism: Clinical and Experimental Research, 25(5), 637-643. https://doi.org/10.1111/j.15300277.2001.tb02261.x

Saroglou, V. (2002). Religion and the five factors of personality: A meta-analytic review. Personality and Individual Differences, 32(1), 15-25. https://doi.org/10.1016/S0191-8869(00)00233-6

Turkheimer, E. (1998). Heritability and biological explanation. Psychological Review, 105(4), $782-791$. https://doi.org/10.1037/0033-295X.105.4.782-791 
Turkheimer, E., Haley, A., Waldron, M., D’Onofrio, B., \& Gottesman, I. I. (2003). Socioeconomic status modifies heritability of IQ in young children. Psychological Science, 14(6), 623-628. https://doi. org/10.1046/j.0956-7976.2003.psci_1475.x

Turkheimer, E., \& Waldron, M. (2000). Nonshared environment: A theoretical, methodological, and quantitative review. Psychological Bulletin, 126(1), 78-108. https://doi.org/10.1037/0033-2909.126. 1.78

Winter, T., Kaprio, J., Viken, R. J., Karvonen, S., \& Rose, R. J. (1999). Individual differences in adolescent religiosity in Finland: Familial effects are modified by sex and region of residence. Twin Research, 2(2), 108-114. https://doi.org/10.1375/twin.2.2.108

Yamagata, S., Suzuki, A., Ando, J., Ono, Y., Kijima, N., Yoshimura, K., Ostendorf, F., Angleitner, A., Riemann, R., Spinath, F. M., Livesley, W. J., \& Jang, K. L. (2006). Is the genetic structure of human personality universal? A cross-cultural twin study from North America, Europe, and Asia. Journal of Personality and Social Psychology, 90(6), 987-998. https://doi.org/10.1037/0022-3514.90.6.987

(Manuscript received 26 March, 2019; Revision accepted 29 June, 2020; Released online in J-STAGE as advance publication 30 October, 2020) 